\title{
OS DIREITOS HUMANOS NO BRASIL SÃO DIREITOS?: UMA ANÁLISE CRÍTICA SOB A PERSPECTIVA DAS TEORIAS DOS DIREITOS HUMANOS E DO REALISMO JURÍDICO
}

\section{Jéssika Saraiva de Araújo Pessoa ${ }^{1}$}

\section{Resumo:}

Este artigo possui como objeto de estudo à efetividade dos Direitos Humanos, a sua materialização na realidade social brasileira, sob a perspectiva das teorias dos Direitos Humanos e do Realismo Jurídico. O problema que se propõe esse artigo é se os Direitos Humanos no Brasil são Direitos? ou meras garantias formais, ideologias a serem alcançadas?. Quando à metodologia, utilizou-se o método dedutivo, o procedimento o monográfico, o objetivo metodológico adotado foi o descritivo, a técnica de pesquisa aplicada foi à revisão bibliográfica e documental. O recorte teórico central são os autores Costa Douzinas, Lorena de Melo Freitas e Benjamin Cardozo.

Palavras-chave: Direitos Humanos; Efetividade; Realismo; Decisão Judicial.

\section{HUMAN RIGHTS IN BRAZIL ARE RIGHTS? A CRITICAL ANALYSIS UNDER THE PERSPECTIVE OF THE THEORIES OF HUMAN RIGHTS AND REALISM}

\begin{abstract}
:
This article has as object of study the effectiveness of Human Rights, its materialization in the Brazilian social reality, from the perspective of Human Rights theories and Legal Realism. The problem that this article proposes is whether human rights in Brazil are Rights? or mere formal guarantees, ideologies to be achieved? When the methodology was used the deductive method, the procedure the monographic, the methodological objective adopted was the descriptive, the applied research technique was the bibliographical and documentary review. The central theoretical cut are the authors Costa Douzinas, Lorena de Melo Freitas and Benjamin Cardozo.
\end{abstract}

Keywords: Human rights; Effectiveness;Realism;Decision Judiciary.

${ }^{1}$ Mestranda em Ciências Jurídicas pela Universidade Federal da Paraíba-UFPB. E-mail: Jessikasaraiva@gmail.com. Agradecimento a CAPES, pelo financiamento da pesquisa.

*Especialista em Prática Jurídica pela ESMA/UEPB.

* Graduada em Direito pela UEPB. 


\section{Introdução}

$\mathrm{Na}$ atualidade a principal dificuldade enfrentada pelos Direitos Humanos se refere a sua eficácia, a sua materialização no contexto social. Tal realidade não é diferente no Brasil, que apesar de positivados na Constituição de 1988, tais direitos enfrentam grandes dificuldades de efetivação, tendo os cidadãos recorrido ao judiciário em busca de sua concretização.

Este artigo tem como objeto de estudo à efetividade dos Direitos Humanos, a sua materialização na realidade social brasileira, sob as perspectivas das teorias dos Direitos Humanos e do Realismo Jurídico. O problema que se propõe esse estudo é: se os Direitos Humanos no Brasil são Direitos? ou meras garantias formais, ideologias a serem alcançadas?. Quando à metodologia, no que diz respeito ao método de abordagem, utilizou-se o dedutivo, o procedimento adotado foi o monográfico, o objetivo metodológico utilizado foi o descritivo, a técnica de pesquisa aplicada foi à revisão bibliográfica e documental.

À hipótese aqui defendida é os Direitos Humanos no Brasil são garantias formais, ideologias a serem conquistadas que não foram concretizadas, não sendo assim Direitos, em razão da sua ineficácia, eles só se tornam direitos ao serem materializados pelo poder judiciário. A estratégia de abordagem adotada são as discussões jurídico-filosóficas a respeito dos Direitos humanos, sob a ótica das teorias dos direitos humanos e do realismo jurídico. $\mathrm{O}$ recorte teórico central são as obras: O fim dos direitos humanos de Costa Douzinas, o artigo, Uma Análise pragmática dos Direitos humanos de Lorena de Melo Freitas e o livro The Nature of Judicial Process de Benjamin N. Cardozo.

Para melhor compreensão das ideias adotada neste artigo dois pontos devem ser destacados, o primeiro diz respeito ao conceito de crítica, a crítica adotada neste artigo tem o objetivo kantiano original de explorar os pressupostos filosóficos, as "condições de existência" necessárias e suficientes de um discurso ou prática em particular. O conceito de critica adotado é o mesmo utilizado por Douzinas (2009,p.21) no livro o Fim dos Direitos Humanos que é um dos referenciais teóricos centrais desse artigo.

O segundo ponto a ser esclarecido é que do ponto de vista metodológico, optamos por uma abordagem descritiva conceituada por Feitosa (2016, p.26) como aquela que examina o direito como efetivamente é e não como deveria ser. $\mathrm{O}$ uso realismo jurídico neste artigo apesar de ele não está plenamente de acordo com o modelo adotado no ordenamento brasileiro que centraliza a produção da norma na figura do legislador e confere ao judiciário a 
competência primordial de aplicação da norma se justifica com um ponto de partida muito relevante para as discussões a respeito da materialização dos Direitos Humanos, visto que o seu problema central em nosso ordenamento diz respeito a sua eficácia.

Ademais, por questões metodológicas esse estudo se divide em quatro tópicos, o objeto central do tópico inicial e introdutório é o processo de reconhecimento e positivação dos direitos humanos nas Constituições modernas e democráticas. Já no segundo tópico o objetivo foi realizar uma discussão crítica sobre os direitos humanos e a sua efetividade. $\mathrm{O}$ terceiro tópico realiza uma discussão crítica sobre a necessidade de fundamento absoluto para os Direitos Humanos e a sua relação com a efetividade desses direitos. O quarto e ultimo tópico deste estudo discute se os Direitos Humanos são Direitos, por meio da perspectiva do realismo jurídico, tendo em vista que o grande problema que eles enfrentam na atualidade diz respeito a sua efetividade.

Destarte, após as abordagens realizadas entendemos que os Direitos Humanos no Brasil são garantias formais, ideologias a serem conquistadas que não foram concretizadas, não sendo assim Direitos, em razão da sua ineficácia, da ausência de materialização na realidade social, eles só se tornam direitos ao serem conferidos aos cidadãos pelo poder judiciário.

\subsection{O Reconhecimento e a Positivação dos Direitos Humanos}

Os Direitos Humanos reconhecidos e positivados nas Constituições Modernas Democráticas são fruto de longo processo histórico e das lutas sociais, foram séculos até eles fossem reconhecidos e positivados nos ordenamentos jurídicos ocidentais, todavia eles ainda enfrentando grandes barreiras, a sua compreensão e aceitação em outras culturas, principalmente na sua pretensão de universalidade diante do relativismo cultural e de outras perspectivas adotadas para a sua compreensão como a multicultural.

No entanto, neste artigo não entraremos em tais discussões de delimitação conceituais dos Direitos Humanos, visto que entendemos que nem o Universalismo, o relativismo e o historicismo, são modelos isolados suficientes para explicar os Direitos Humanos, não há um modelo único que possa ser considerado apto, assim sendo partilhamos da ideia de que nenhum desses modelos conseguirá atribuir um sentido absoluto e inquestionável a esses direitos.

O objeto central deste tópico inicial e introdutório é o processo de reconhecimento e positivação dos direitos humanos nas constituições modernas e democráticas, as discussões que serão realizadas a seguir concentram-se nesse tema. De acordo com Lafer $(2006,14)$ 
existem etapas de afirmação dos Direitos Humanos que são sumariadas por ele em Positivação, Generalização, Especificação e Internacionalização, neste tópico trataremos apenas do reconhecimento e da positivação que é definida pelo autor como a conversão da aspiração em prol dos direitos humanos em Direito Positivo.

Quando nos referimos, a positivação dos Direitos Humanos, ao Direito positivo, estamos adotando definição realizada por Bobbio (1995 p. 131-132) estamos falando de uma proposta de estudo do direito como uma ciência, de forma avalorativa, sendo ele um fato social, e a legislação como sua fonte preeminente, as normas são feitas valer por meio da força, o direito é definido em função da sua coação, da exigibilidade da norma. Assim sendo, quando nos remetemos à positivação dos Direitos Humanos nas Constituições Democráticas modernas, estamos nos referindo a esse processo de transformação de aspirações em normas.

No que diz respeito ao seu reconhecimento, inicialmente, os Direitos Humanos estavam ligados a interesses da burguesia emergente no século XVIII e foram às armas ideológicas dessa classe, na sua luta pela participação no poder e contra o poder político despótico, foram os argumentos utilizados na defesa da sua pretensão de que o poder político deve estar sujeito às exigências da razão e da lei e como consequência passaram a fazer parte da principal ideologia da maioria dos regimes contemporâneos (DOUZINAS, 2009, p.19).

Segundo Bobbio (2004, p.7) os Direitos do homem são direitos históricos que surgem na era moderna juntamente com a concepção individualizada de sociedade, sendo um dos principais indicadores do progresso histórico, eles derivam de uma radical mudança de perspectiva trazida pelo Estado moderno na relação de súdito e soberano que é convertida em uma relação entre Estado e cidadãos.

Essa relação conforme o autor passa a ser encarada cada vez mais do ponto de vista dos direitos dos cidadãos, fruto da visão individualista de sociedade que defende que para se compreender a sociedade é necessário se compreender primeiro o individuo, tal concepção se contrapõe a orgânica de sociedade que compreende a sociedade como um todo antes do indivíduo. Assim sendo, para Bobbio é a concepção individualista de sociedade que nos leva ao reconhecimento dos direitos dos cidadãos de cada Estado e lentamente ao reconhecimento dos direitos do cidadão do mundo (BOBBIO, 2004, p.7).

Ainda, consoante o mesmo autor o reconhecimento dos direitos humanos e a sua positivação por meio das declarações de direitos pode se distinguir em pelo menos três fases, visto que as declarações nascem como teorias filosóficas. A primeira fase se expressa na obra 
dos filósofos, em teorias filosóficas, na ideia de que o homem enquanto tal tem direito, por natureza, que ninguém, nem mesmo o Estado lhe pode subtrair, e que ele mesmo não pode alienar, visto que mesmo em estado de necessidade a sua transferência não é válida, essa ideia foi elaborada pelo Jusnaturalismo moderno tendo como autor John Locke (BOBBIO, 2004, p.18).

Ademais, as primeiras afirmações dos direitos do homem são universais em relação ao conteúdo, na medida em que se dirigem a um homem racional fora do espaço e do tempo, no entanto são extremamente limitadas em relação à sua eficácia, na medida em que são apenas propostas para um futuro legislador, essas teorias só são acolhidas pela primeira vez pelo legislador por meio das Declarações de Direitos dos Estados Norte-americanos e da Revolução Francesa, sendo consideradas a base de uma nova concepção do Estado que tem seus poderes limitados. Em consequência disto à afirmação dos direitos do homem passa a não ser mais expressão de uma nobre exigência, mas o ponto de partida para a instituição de um autêntico sistema de direitos positivos. (BOBBIO, 2004, p.18).

Já o segundo momento se caracteriza pela passagem da teoria à prática, na preocupação com a concretização dos Direitos Humanos, todavia essa positivação dos direitos no âmbito do estado resulta em redução de sua universalidade, visto que esses direitos reconhecidos e positivados possuem validade apenas no âmbito do Estado que os reconhecem (BOBBIO, 2004, p.19).

A terceira e ultima fase apontada pelo autor possui como marco inicial, a Declaração de 1948, ela se caracteriza pela afirmação dos direitos que são ao mesmo tempo, universais e positivos, tendo como destinatários dos princípios nela contidos todos os homens e não mais apenas proclamados ou somente idealmente reconhecidos, porém efetivamente protegidos até mesmo contra o próprio Estado que os tenha violado (BOBBIO, 2004,p.19).

E por fim, conforme Bobbio (2004, p.19) ao final desses processos os direitos do homem serão direitos dos cidadãos do mundo, visto que para o autor os direitos do homem nascem como direitos naturais universais, desenvolvem-se como direitos positivos particulares, para finalmente encontrarem sua plena realização como direitos positivos universais. Dessa forma, a Declaração Universal representa a síntese de um movimento dialético.

Além disso, ainda sobre a positivação dos direitos humanos, o autor acrescente que em seu Preâmbulo a declaração de 1948, afirma que é indispensável que os direitos do homem sejam protegidos por normas jurídicas com o objetivo de evitar que o homem seja obrigado a Rev. de Teorias do Direito e Realismo Jurídico | e-ISSN: 2525-9601| Goiânia| v. 5 | n. 1 | p. 45-65| Jan/Jun. 
recorrer, como última instância, à rebelião contra a tirania e a opressão. Ademais, cumpre destacar que o processo de Constitucionalização dos Direitos Humanos e a proteção jurídica de alguns desses direitos, o direito natural de resistência transformou-se no direito positivo que temos de promover uma ação judicial contra os próprios órgãos do Estado pelo cidadão para a garantia da defesa e efetividade de seus direitos (BOBBIO, 2004,p.19).

No entanto, nem todos os Estados reconheceram os Direitos Humanos como Direitos dignos de proteção ou mesmo a sua universalidade e neles aos cidadãos só resta o chamado direito de resistência. Nesses casos somente há proteção desses direitos num degrau mais alto do que o Estado, ou seja, na comunidade internacional. (BOBBIO, 2004,p.19).

Sem duvidas a Declaração Universal 1948 é um marco na positivação dos direitos do homem, após o seu reconhecimento e positivação as grandes dificuldades que esses direitos passaram a enfrentar dizem respeito a implementação de medidas eficientes para a sua garantia na comunidade internacional, na qual, diferentemente dos Estados modernos ainda não ocorreu o processo de monopolização da força, não existindo um órgão internacional responsável por punir aqueles que os violarem ou mesmo uma coercibilidade. Dessa maneira, tais direitos seriam meras declarações formais.

Outro problema, apontado por Bobbio (2004,p.21) se refere ao próprio conteúdo da Declaração, ou seja, à quantidade e à qualidade dos direitos elencados, a Declaração não pode apresentar nenhuma pretensão de ser definitiva, visto que os direitos do homem são direitos históricos, que emergem gradualmente das lutas que o homem trava por sua própria emancipação e das transformações das condições de vida que essas lutas produzem, sendo assim direitos dinâmicos e em constante transformação para atender as demandas sociais .

Assim sendo, segundo Bobbio (2004, p.20) os Direitos Humanos são o produto não da natureza, mas da civilização humana e enquanto direitos históricos, eles são mutáveis, ou seja, suscetíveis de transformação e de ampliação. Basta examinar os escritos dos primeiros jusnaturalistas para ver quanto se ampliou a lista dos direitos.

A sua classificação em gerações demostra o processo de ampliação desses direitos de acordo com as transformações da sociedade, nesse sentido Lafer (2006, p.14) acrescenta que essa positivação foi acompanhada pelo reconhecimento de uma graduação hierárquica do valor dos direitos humanos, dessa forma o autor classifica esses direitos em gerações que foram gradativamente sendo positivadas. 
Conforme Lafer (2006, p.15) a primeira geração ${ }^{2}$ de Direitos positivados foram os civis e políticos, e eles são resultado das limitações impostas pelo direito à discricionariedade do poder dos governantes e da visão de mundo do liberalismo, no século XIX, da distribuição do poder político, econômico e cultural entre os governados e da ascensão da burguesia

Em seguida a segunda geração de direitos que foram positivados são os direitos econômicos, sociais e culturais que são fruto do legado do socialismo e dos imperativos da justiça social que se inseriram na agenda política no século XIX e no século XX. Esses direitos representam uma forte critica ao formalismo e são fruto de uma exigência de igualdade concreta, de o individuo participar do estado de bem estar social. Já a terceira geração de direitos surge no plano internacional, são os direitos de titularidade coletiva, considerados direito de solidariedade, são eles o direito a paz, ao desenvolvimento, a autodeterminação dos povos, eles são resultado da revolução intelectual do século XX. (LAFER, 2006, p.15-16).

Outros autores realizam classificações de novas gerações como Direitos humanos de quarta e quinta geração, não há um consenso doutrinário a seu respeito como existe nas três gerações reconhecidas inclusive pelo Supremo Tribunal Federal. A quarta geração segundo Sarlet (1998, p. 52) seria o direito contra a manipulação genética, direito de morrer com dignidade e direito à mudança de sexo, esses novos direitos são fruto dos novos conflitos jurídicos da sociedade contemporânea, sendo assim uma tentativa de solucioná-los, todavia há, ainda, doutrinadores, que entendem que a quarta geração de direitos de outras maneiras.

Os Direitos Humanos da quinta geração são classificados por Sarlet (1998, p. 52) como o direito, a honra, a imagem, os direitos de personalidade em geral e os direitos virtuais que ressaltam do princípio da dignidade da pessoa humana, tais direitos tem sua origem com o desenvolvimento da Internet nos anos 90 e novas demandas sociais oriundas delas.

Para Lafer(2006, p.14) o processo de reconhecimento e positivação gradual dos Direitos Humanos, consoante exposto acima por meio das gerações, está inter-relacionado, a existência da Democracia e o Estado de Direito que ensejam a garantia de sua tutela, ou seja, o reconhecimento e a positivação dos Direitos humanos é uma característica essencial dos Estados democráticos de Direito.

\footnotetext{
${ }^{2}$ A teoria das gerações foi desenvolvida por Karel VASAK por meio de um texto publicado em 1977, bem como por uma palestra proferida em 1979. Tal palestra e fruto de uma Conferência no Instituto Internacional de Direitos Humanos de Estrasburgo (França) - 1979: 'e é denominada de "Pelos Direitos Humanos da Terceiração Geração: os direitos de solidariedade".
} 
No mesmo sentido é compreensão de Bobbio (2008, p.7) que afirma que a paz é um pressuposto para o reconhecimento e para a proteção dos Direitos homem em cada Estado e no sistema internacional. Sem direitos do homem não há democracia, sem democracia não há paz, esses são três momentos necessários do mesmo momento histórico.

Dessa maneira, a constitucionalização dos direitos humanos está intimamente ligada ao Estado Democrático de Direito, sendo uma de suas características essenciais, no caso do Brasil esses direitos são considerados cláusulas pétreas. (LAFER, 2006, P.15).

No Brasil, o reconhecimento e a positivação dos Direitos Humanos em nossa Carta maior é fruto de um processo de redemocratização recente e da instituição do jovem Estado Democrático de Direito pela Constituição de 1988, após, o regime autoritário que perdurou nas décadas de 1960 a 1990, sob forte influência da Guerra Fria e das politicas expansionistas americanas de combate às ideias socialistas nos países latinos. Todavia, essa transição democrática não resultou necessariamente na instituição integral da democracia, nem do Estado Democrático de Direito, que ainda hoje encontra grandes dificuldades em sua efetivação.

Em nosso país, conforme CASTRO (2012, p.559) o movimento das "diretas já" ganhou força em 1984, o que resultou na Constituição de 1988, a Constituição Cidadã, que possui como objetivo a garantia dos direitos fundamentais, e como núcleo axiológico a dignidade da pessoa humana, constituindo-se, assim, um Estado Democrático de Direito.

Esse Estado, no entanto, encontra grandes dificuldades em sua concretização, visto que nos primeiros sintomas de crise, os direitos fundamentais são questionados e violados em virtude uma proteção deficiente que obriga os cidadãos a buscar sua consolidação, muitas vezes por meio do Judiciário. A dificuldade de estabilização do Estado Democrático de Direito é uma característica comum aos países da América Latina, de democracias recentes e fragilizadas, que enfrentam grandes barreiras para a efetivação dos direitos fundamentais, como resultado do que SCHWARZ (2005, p.2) denomina de "ideias fora de lugar".

No Brasil, ao analisarmos o histórico das Constituições, constatamos fortes influências das ideias imperialistas do Além-Mar. Apropriamo-nos continuamente de ideais europeias e americanas, na maioria das vezes em sentido impróprio. A realidade cultural e social brasileira muito difere da europeia e americana, o que inviabiliza a aplicação de tais padrões que enfrentam dificuldades para a sua efetividade (SCHWARZ, 2005, p. 29). 
O Brasil, como consequência do Constitucionalismo Social do século XX, que promoveu a evolução do modelo de Estado Liberal (passivo) para o Social (intervencionista) adota, quanto a sua extensão, uma Constituição Dirigente, sob forte influência do Constitucionalismo português de 1976 e da doutrina Europeia (CANOTILHO, 1998, p.1351).

A Constituição Dirigente se volta à garantia do existente, aliada a instituição de um programa ou linha de direção para o futuro, sendo estas suas duas finalidades. Ou seja: contém metas que devem ser cumpridas no futuro com o auxílio dos poderes Legislativo e Executivo para o seu integral cumprimento. A nossa Constituição cidadã de 1988, além de adotar um modelo de Estado Social, com o objetivo de garantir os direitos fundamentais dos cidadãos, também institui um Estado Democrático de Direito. Dessa forma, nossa Carta atual almeja a efetivação de um Estado Liberal, Social e Democrático, unindo assim esses três modelos.

Entretanto, as políticas adotadas no Brasil não conseguiram colocar em prática aquilo que as sua Constituição prevê, havendo falhas estruturais do poder público na concessão dos direitos dos cidadãos que passaram a pleiteá-los por via judicial. Diante do exposto, observamos que o reconhecimento e a positivação dos Direitos Humanos tanto na esfera nacional, especificamente no Brasil, como na esfera internacional, ou seja, a sua formalização, não é suficiente, visto que não resultou em sua materialização, em sua efetividade. $O$ problema da efetividade dos direitos humanos será objeto de discussão e explorado no próximo tópico.

\subsection{A Crítica aos Direitos Humanos e o Problema da sua Efetividade}

Antes de adentrarmos as discussões que serão realizadas neste segundo tópico, é necessário esclarecer preliminarmente dois pontos que são essenciais para compreensão das ideais que vão ser tratadas nesta segunda parte que possui como objetivo realizar uma discussão crítica sobre os direitos humanos e a sua efetividade.

Dessa forma, cabem aqui dois pontos iniciais. O primeiro diz respeito ao conceito de crítica, a crítica adotada neste artigo tem o objetivo kantiano original de explorar os pressupostos filosóficos, as "condições de existência” necessárias e suficientes de um discurso ou prática em particular. O conceito de critica adotado é o mesmo utilizado por Douzinas (2009,p.21) no livro o Fim dos Direitos Humanos que é o referencial teórico central deste estudo. É este o tipo de crítica que buscamos exercitar primeiramente, antes de passar para a crítica da ideologia ou à crítica dos direitos humanos. 
O segundo ponto a ser esclarecido é que do ponto de vista metodológico, optamos por uma abordagem descritiva conceituada por Feitosa (2016, p.26) como aquela que examina o direito como efetivamente é e não como deveria ser. Esclarecidos estes pontos adentremos as discussões objeto deste tópico. Na atualidade, consoante Douzinas $(2009$, p.1) um novo ideal foi alardeado no cenário do mundo globalizado, muitos grupos e indivíduos traduziram suas reivindicações na linguagem dos direitos humanos.

Os direitos humanos se tomam o princípio de libertação da opressão e da dominação, o grito de guerra dos sem-teto e dos destituídos, o programa político dos revolucionários e dos dissidentes. Mas o seu apelo não se restringe aos desventurados da terra. Estilos de vida alternativos, vorazes consumidores de bens e cultura, hedonistas que também atendem ao seu chamado (DOUZINAS, 2009, p.1).

Ademais, segundo o autor os direitos humanos são o fado da pós-modernidade, a energia das nossas sociedades, o cumprimento da promessa do Iluminismo de emancipação e autorrealização, a mais nobre criação de nossa filosofia e jurisprudência e como a melhor prova das aspirações universais da nossa modernidade, que teve de esperar por nossa cultura global pós-moderna para ter seu justo e merecido reconhecimento. (DOUZINAS, 2009, p.1).

Além disto, Douzinas descreve que os dois últimos movimentos mundiais a desafiar a democracia liberal, foram o comunismo que teve o seu colapso e o apartheid que foi eliminado, os direitos humanos venceram as batalhas ideológicas da modernidade. Sua aplicação universal e seu total triunfo parecem ser uma questão de tempo e de ajuste entre o espírito da época e uns poucos regimes recalcitrantes. Sua vitória não é outra que não o cumprimento da promessa iluminista de emancipação pela razão, Mas segundo Douzinas essas afirmações nos trazem dúvidas, será ? (DOUZINAS, 2009, p.20).

Diante desse contexto ele questiona se o século XX é realmente a era dos direitos humanos, visto que seu triunfo é, no mínimo, um paradoxo, uma vez que temos testemunhado nesse século mais violações de seus princípios do que qualquer uma das épocas anteriores, o século XX é descrito por ele como o século do massacre, do genocídio, da faxina étnica, a era do Holocausto (DOUZINAS, 2009, p.20).

Nesse mesmo sentido o autor argumenta que em nenhuma outra época da história houve um hiato maior entre os pobres e os ricos no mundo ocidental, e entre o Norte e o Sul globalmente, nunca tantos homens, mulheres e crianças foram subjugados, passaram fome e foram exterminados sobre a terra. Dessa maneira, o escárnio e ceticismo das pessoas não é 
surpreendente diante das afirmações de preocupação de governos e organizações internacionais a respeito desses direitos. (DOUZINAS, 2009, p.20).

Mas será que nossa experiência da imensa lacuna entre a teoria e a prática dos direitos humanos deve fazer com que duvidemos dos seus princípios e questionemos a promessa de emancipação pela razão e pelo direito quando parece estarmos próximos de sua vitória final? (DOUZINAS, 2009, p.20).

Nessa perspectiva crítica em relação ao reconhecimento sem eficácia de tais direitos como meras garantias formais sem comprometimento com a sua concretização que o autor nos leva a reflexão a respeito do maior problema dos direitos humanos em nossa época diz respeito a sua não aplicabilidade, tal como sobre as premissas filosóficas do discurso por traz de tais direitos, a natureza, a função e a ação dos direitos humanos, de acordo com o liberalismo e seus muitos críticos filosóficos. Questionando se os direitos humanos são uma forma de política?.

Com objetivo de apontar possíveis respostas a tais questões o autor explica que os direitos humanos podem ser examinados a partir de duas perspectivas relacionadas, mas relativamente distintas: uma subjetiva e outra institucional. Por um lado, elas ajudam a constituir o sujeito (jurídico) livre e ao mesmo tempo subordinado à lei. Mas os direitos humanos são também um discurso e uma prática poderosos no Direito Nacional e no Internacional. (DOUZINAS, 2009, p.22).

Na medida em que os direitos humanos são discursos e que não existem discursos sem fundo ideológico ${ }^{3}$, então eles podem ser utilizados a serviço de determinadas ideologias, e podem ser utilizados a serviço da politica, do liberalismo, do capitalismo e dos interesses econômicos, ou até mesmo a serviço das guerras. Todavia, a crítica do autor aos direitos humanos é positiva na medida que nos leva a refletir sobre os problemas enfrentados para efetivação desses direitos na atualidade, por que só por meio desta reflexão poderemos buscar alternativas para garantir a efetivação desses direitos e evitar que eles sejam utilizados como ferramentas ideológicas.

Sobre essa perspectiva crítica dos direitos humanos Freitas no mesmo sentido que Douzinas destaca que a limitação do programa, hoje majoritário dos Direitos humanos consiste na sua base individualista, egoística e liberal. Segundo a autora tais direitos não

\footnotetext{
${ }^{3} \mathrm{O}$ termo ideologia é aqui tratado no sentido que Marx e Engels lhe atribuem de imagem invertida da realidade, ou seja, da metáfora utilizada em seus inscritos do fenômeno óptico da inversão da imagem na retina ou na câmera escura de máquina fotográfica. MARX. Karl; ENGELS, Friedrich. A ideologia Alemã: Teses sobre Feuerbach. São Paulo: Centauro, 2005, p.26.
} 
podem ser utilizados como ideologia de justificativa dos ricos para explicar intervenção contra os países pobres, os direitos humanos não podem ser utilizados como instrumentos de apropriação de riquezas, como mera estrutura de justificação para garantir a conservação de estruturas sociais perversas. (FREITAS, 2012, p.228-230).

Ademais, a autora acrescenta que falar de direitos enquanto garantias formais nada mais são do que discursos ideológicos de manutenção do status quo, visto que ampla maioria da humanidade não possui sequer direito algum, tal programa de direitos humanos se torna herdeiro da tradição liberal e individualista do século XVIII, uma mera ideologia para justificar desigualdades e atrocidades estimular passividade e falsas esperanças de mudanças dentro dessa ordem social (FREITAS, 2012, p.232-233).

Nesse mesmo sentido, a autora levanta a hipótese de que não que se falar em soluções para os Direitos humanos, visto que a ineficácia deles é praticamente conditio sine qua non de sua própria existência enquanto estes direitos cumprem um papel de linguagem de segunda ordem dentro do mundo jurídico. Diante do exposto a autora conclui que os direitos humanos tem sido um discurso político-jurídico e quase retórico que enaltece a própria ordem jurídica e não podem ser elevados ao patamar de tábua de salvação da humanidade, do direito e da sociedade, uma vez que o próprio direito não pode ser percebido sem as desigualdades econômicas e sociais sob as quais ele fundamenta, uma vez que ele é o meio de legitimação da propriedade privada de bens (FREITAS, 2012, p.234-236).

Assim sendo, se o próprio direito parte da condição de desigualdade, se perfaz na sustentação de desigualdades, mesmo que os homens aparentem ser o seu fim e o meio deles, quem são os humanos dos DDHH?. Não são todos os humanos que figuram efetivamente como seus destinatários, para alguns humanos apenas as garantias formais são aplicadas é a sociedade paradoxal e negativa mundial quem define quem é de um modo geral um ser humano e por consequência quais são os Direitos Humanos (FREITAS, 2012, p.239). Por conseguinte, dentro desta perspectiva crítica e realista dos Direitos humanos nos filiamos as ideais da autora a respeito das dificuldades de materialização dos direitos humanos e de que o discurso a respeito dos DDHH não é um discurso neutro.

\subsection{A Necessidade de um Fundamento Absoluto para os DDHH e o Problema da sua}

\section{Efetividade}

Este terceiro tópico é relevante por que possui como objetivo realizar uma discussão crítica sobre a necessidade de fundamento absoluto para os Direitos Humanos e a sua relação 
com a efetividade desses direitos. A busca de um fundamento absoluto é a solução adequada para se obter o reconhecimento dos DDHH e principalmente a sua eficácia? Nossa maior preocupação deve ser com o seu fundamento absoluto ou em como protegê-los?.

Consoante Bobbio (2004, p.12) a busca de fundamento absoluto para os direitos humanos, nasce da ilusão de um argumento irresistível, o qual ninguém recusaria adesão, todavia, a busca de tal fundamento enfrenta quatro dificuldades. A primeira dificuldade explanada pelo autor se refere à dificuldade ou "má" definição dos direitos humanos, visto que trata-se de uma expressão vaga, de difícil definição, que resulta em redundância em ciclos viciosos. Ele cita como exemplo a expressão “São Direitos do Homem em quanto Homem”( BOBBIO, 2004, p.13).

Dessa maneira, o autor conclui que nenhuma destas definições nos permite a elaboração de contornos nítidos, ausência de uma definição precisa impossibilita a solução do problema do fundamento absoluto (BOBBIO, 2004, p.13).

A segunda dificuldade apontada por Bobbio diz respeito aos direitos humanos terem como característica o relativismo histórico, o rol de direitos do homem se modificou e vem se modificando ao longo da história. Mesmo aqueles que já foram declarados absolutos, a exemplo da propriedade foram submetidos às limitações das declarações contemporâneas e novos direitos irão surgir das novas demandas sociais, ou seja, o que se aplica a uma época não pode ser aplicado à outra (BOBBIO, 2004, p.13).

Assim sendo não é possível se atribuir um fundamento absoluto a direitos que são historicamente relativos. Foi relativismo que possibilitou o surgimento de direitos como a liberdade de expressão e a religiosa (BOBBIO, 2004, p.14). A terceira dificuldade exposta se traduz no fato de os Direitos Humanos serem considerados por Bobbio (2004, p.15) como heterogêneos, ou seja, entre eles existem pretensões diversas entre si, ou até mesmo incompatíveis, não se podendo falar em fundamento único, mas sim em fundamentos que podem mudar conforme o direito e as razões que se pretende defender.

Segundo Bobbio (2004, p.15) existindo em muitas situações o conflito entre direitos fundamentais que não são absolutos, nesse sentido direitos com diferentes eficácias não podem ter o mesmo fundamento. A quarta e ultima dificuldade é definição desses direitos pelo autor como antinômicos, o que significa que o desenvolvimento de alguns desses direitos não pode ser feito paralelamente, uma vez que a realização integral de uns impede a dos outros. (BOBBIO, 2004, p.15). 
Por fim, Bobbio(2004, p.16) conclui que o fundamento absoluto é uma ilusão e pode mascarar posições conservadoras e impedir o desenvolvimento de novos direitos, além disto e no lugar de um fundamento absoluto, inquestionável, devemos buscar a sua prática, a efetividade desses direitos e os meios de protegê-los.

Partilhamos dessa posição do autor, em nosso entendimento a principal dificuldade enfrentada pelos Direitos humanos, ou mesmo os Direitos fundamentais (que são os direitos humanos positivados no âmbito do Estado), diz respeito a sua aplicabilidade e a sua coercibilidade no âmbito internacional. Assim sendo, nosso maior desafio é proteger esses direitos, e nossa maior questão passa a ser qual a forma mais segura de garantir esses direitos?.

Dessa maneira, apesar de estarem consagrados em solenes declarações, eles são violados seja na esfera do Estado ou na internacional, o maior problema de nossa época não é se esses direitos são universais, relativos, históricos, ou mesmo sua fundamentação, reconhecimento ou positivação, mas sim a sua garantia.

\subsection{Os Direitos Humanos São Direitos no Brasil? : Uma Análise sob a Perspectiva do Realismo Jurídico}

O quarto e ultimo tópico deste artigo possui como objetivo central discutir se os Direitos Humanos são Direitos por meio da perspectiva do realismo jurídico, tendo em vista que o grande problema que eles enfrentam na atualidade diz respeito a sua efetividade. Inicialmente cumpre esclarecer que o conceito de Direito adotado neste estudo se filia a perspectiva positivista de coação como elemento essencial e típico dele. E da ideia de que o que distingue o direito da moral é sua coercibilidade.

Conforme as modernas teorias da coação que possuem como maiores expoentes Kelsen e Ross, o direito é um conjunto de regras que tem por objeto a regulamentação do uso da força numa sociedade, este conceito de direito trazido por Bobbio $(1995$, p.157) é o que adotamos no presente artigo.

Após esclarecer a perspectiva de direito adotada neste estudo iniciamos nossas considerações a respeito do realismo jurídico que é uma corrente do pensamento jurídico contemporâneo que pertence ao positivismo jurídico em sentido genérico e se diferencia dele em sentido estrito, tendo como principal característica a preocupação com a efetividade, com a aplicação prática dos Direitos, assim como o positivismo jurídico tem como preocupação 
central a validade da norma, o realismo tem como seu ponto central a sua eficácia (BOBBIO,1995, p.142).

Na concepção realista a definição de direito baseada no requisito único de validade é insuficiente, para essa corrente de pensamento é necessário à introdução do requisito da eficácia. Para os realistas, o Direito é um fato social, uma realidade social, uma realidade de fato, e sua função é ser aplicado, dessa forma, uma norma que não é aplicada que não possui eficácia não é considerada Direito para essa escola realista do direito (BOBBIO,1995, p.142).

O direito pode ser definido na concepção realista "como o conjunto de regras que são efetivamente seguidas em uma determinada sociedade". Dessa forma, os realistas enfocam o direito sob o ponto de vista do "ser" e não do "dever ser" como os positivistas. Ao tratarem da eficácia do Direito, os realistas estão se referindo ao comportamento dos juízes, visto que as normas são aquelas que os juízes aplicam no exercício de sua função, assim sendo o ordenamento jurídico é aquele composto pelos que os juízes aplicam e não pelo que o legislador produz e não tem eficácia. (BOBBIO,1995, p.142-143).

O pensamento realista apesar de não está plenamente de acordo com o adotado no ordenamento brasileiro que centraliza a produção da norma na figura do legislador e confere ao judiciário a competência primordial de aplicação da norma é um ponto de partida muito relevante para as discussões a respeito da materialização dos Direitos Humanos, visto que o seu problema central em nosso ordenamento diz respeito a sua eficácia.

As tentativas de materialização dos Direitos Humanos por meio do poder judiciário no Brasil tem representado uma aproximação do Direito Brasileiro com o Common Law, nas quais as premissas realistas são aplicadas como no Direito norte americano. Como exemplo de violação de Direitos Humanos positivados em nossa Carta maior (Direitos Fundamentais) no Brasil e da atuação atípica do poder judiciário podemos citar o reconhecimento, de forma parcial pelo Supremo Tribunal Federal (STF) do Estado de Coisas Inconstitucional (ECI), diante do gravíssimo quadro de violação aos direitos humanos dos presos em nosso país. A teoria do Estado de Coisas Inconstitucional (ECI) foi adotada recentemente pela nossa Suprema Corte Constitucional.

O reconhecimento em sede de medida cautelar, de forma parcial pelo Supremo Tribunal Federal (STF) do Estado de Coisas Inconstitucional (ECI) ocorreu em maio de 2015, por meio da ação Arguição de Descumprimento de Preceito Fundamental (ADPF 347) proposta pelo Partido Socialista e Liberdade (PSOL), na qual se postulava a declaração de que a situação atual do sistema penitenciário brasileiro viola preceitos fundamentais da Rev. de Teorias do Direito e Realismo Jurídico | e-ISSN: 2525-9601| Goiânia| v. 5 | n. 1 | p. 45-65| Jan/Jun. 
Constituição Federal (diversos direitos fundamentais dos presos) e, em razão disso, requeriase que o tribunal determinasse providências com o objetivo de sanar essas graves lesões aos direitos dos presos.

O Estado de Coisas Inconstitucional (ECI) pode ser definido, conforme Campos (2015, p.2), como um mecanismo ou uma técnica jurídica de origem jurisprudencial, adotada inicialmente pela Corte Constitucional da Colômbia na sentença $n^{\circ}$ SU-559, de 6/11/19973, na qual a suprema corte reconhece a existência de um Estado de Coisas Inconstitucional, ou seja, um conjunto de violação aos direitos fundamentais que ultrapassa a esfera da simples omissão inconstitucional por parte de uma esfera do Poder Público e consiste numa falha estrutural e generalizada na concessão desses direitos, que não poderia ser atribuída a um único órgão e afeta um número indeterminado de pessoas, geralmente um grupo vulnerável. Ao declarar o ECI, além de defender os direitos do grupo envolvido, a corte procurou proteger as dimensões objetivas e subjetivas dos direitos fundamentais.

Além disso, Sarmento (2015, p.17) ressalta na ADPF 347 que a situação carcerária brasileira é visivelmente incompatível com a Constituição de 1988, a carta cidadã, visto que viola diretamente preceitos fundamentais consagrados por ela, tais quais: o princípio da dignidade da pessoa humana (art. $1^{\circ}$, III), a vedação à tortura $\mathrm{e}$ ao tratamento desumano ou degradante (art. 5 $5^{\circ}$, III), as sanções cruéis (art. 5 $5^{\circ}$ XLVII, “e”), a previsão de cumprimento da pena em estabelecimentos distintos, de acordo com a natureza do delito, a idade e sexo do apenado (art. $5^{\circ}$, XLVIII), o direito dos presos ao respeito a sua integridade física e moral (art. $5^{\circ}$, XLIX) e a presunção de inocência (art. $5^{\circ}$, LVII). Igualmente, inúmeros outros direitos fundamentais como saúde, educação, alimentação adequada e acesso à justiça são negados à população carcerária.

Nesse sentido, a corte superior ainda não julgou definitivamente o mérito da ADPF, mas já apreciou liminarmente os oito pedidos realizados e decidiu conceder parcialmente a tutela requerida através dos pedido de redução do número de prisões provisórias por meio da motivação das prisões pelos magistrados com as justificativas para não adoção de medidas cautelares alternativas à privação da liberdade, de realização de audiência de custódia e da liberação das verbas do Fundo Penitenciário (FUNPEN). Já os pedidos que envolviam tempo de prisão foram considerados insubsistentes devido à falta de previsão legal que alicerçasse o seu acolhimento. 
Destarte, apesar das ponderações do STF na medida cautelar, o reconhecimento do ECI gerou grandes discussões a respeito da materialização dos Direitos Fundamentais no Brasil, sobre o papel do Poder Judiciário na concretização desses direitos e os limites a sua atuação.

Levantando questões como a de que se o poder judiciário pode impor aos demais o cumprimento de Direitos humanos positivados em nossa Constituição?. Em um Estado no qual existem graves violações aos Direitos Humanos reconhecidos e positivados, a solução mais adequada para a efetivação desses direitos sem eficácia é a imposição por parte do judiciário de politicas para a materialização de tais Direitos?. Seria está a melhor solução para a problemática da efetividade dos Direitos Humanos? Essa "atuação supostamente não democrática" é só é negativa? Ou existem aspectos positivos no que os doutrinadores denominam de Ativismo e ele pode ser considerado uma ferramenta de concretização de Direitos Humanos que o judiciário vem recorrendo para materialização de tais Direitos?

Ao analisarmos o reconhecimento ECI entendemos que a atuação ativista não é apenas negativa, ela possibilita a concretização de direitos de fundamentais de minorias estigmatizadas, todavia, o grande problema que o ativismo evidencia é a falta de efetividade dos Direitos Humanos no Brasil e um verdadeiro Estado de Coisas Inconstitucional generalizado no que diz respeito à concretização de direitos fundamentais.

Tal quadro se torna preocupante na medida em que o reconhecimento e positivação de tais direitos no Brasil não se mostrou como meio suficiente para a garantia de sua efetividade e o grande desafio enfrentado pelo Brasil na atualidade é a concretização a materialização desses direitos essências a dignidade humana, a aplicação de direitos de tamanha relevância não pode ficar condicionada a discricionariedade do poder judiciário que está sujeito as interferências políticas, esse conteúdo político pode transformar o poder judiciário em ditadura institucional que atende aos interesses de um partido ou grupo e tornar os direitos humanos um discurso político a serviço de interesses particulares o que sem duvidas é uma ameaça ao Estado Democrático de Direito

A ausência de sanções internacionais, de uma coercibilidade, ao Estado Brasileiro pelo descumprimento de tais direitos é outro fator que contribui para o Estado de Coisas Inconstitucionais generalizado que o Brasil vive. Assim sendo, após as considerações realizadas acima podemos confirmar a hipótese aqui defendida de que os Direitos Humanos no Brasil são garantias formais, ideologias a serem conquistadas que não foram concretizadas, 
não sendo assim Direitos, em razão da sua ineficácia, eles só se tornam direitos ao serem materializados pelo poder judiciário por meio de suas decisões, a exemplo do ECI.

Tal hipótese, sob a perspectiva do realismo jurídico, que possui como principal característica a preocupação com a efetividade, com a aplicação prática dos Direitos foi confirmada, os direitos humanos sob a perspectiva do realismo jurídico não são direitos no Brasil, visto que carecem de aplicação concreta. Os Direitos humanos não podem ser utilizados como mecanismo de dominação e discurso de justificação das desigualdades, sob pena de perder o seu objeto central que é a garantia da Dignidade Humana.

Além disto, como nos adverte Cardozo (2004, p.02) na estranha mistura produzida pelos caldeirões dos tribunais diariamente, existem ingredientes que participam em proporções variadas e eles não se reúnem por acaso, algum princípio ainda que inconfesso e não articulado e subconsciente orientou o preparo da infusão, houve uma escolha, e os motivos que a determinaram, muitas vezes obscuros não resistem plenamente à análise, ou seja, existem elementos psicológicos que influenciam nas decisões judicias, eles também são ingredientes dessa mistura preparada pelos juízes.

O autor acrescenta que existem forças que por se encontrarem tão abaixo da superfície só podem ser classificadas como subconscientes, os juízes como todos os seres humanos ao longo de sua existência são levados por forças que não conseguem reconhecer ou identificar, são eles instintos herdados, crenças tradicionais, convicções adquiridas, em resumo um estilo de vida, uma percepção das necessidades sociais, dessa maneira, esses elementos fazem parte também dos ingredientes que compõe o caldeirão dos tribunais (CARDOZO, 2004, p.03).

No mesmo sentido, acrescente Freitas (2015, p.61) que nesse processo de infusão também são transmitidas ideologias. Todavia, a autora adverte que apesar de para Cardozo a norma feita pelo juiz ser uma realidade da vida, seria um erro grosseiro, sob a ótica realista, acreditar que os juízes decidem suas causas de forma aleatória e de acordo apenas com suas convicções desprezando que existam fatores e mecanismos garantidores de segurança jurídica (FREITAS, 2015, p.88).

Ademais, a autora acrescenta que a abordagem de Cardozo a respeito de como os juízes decidem suas causas, especificamente os elementos subconscientes no processo judicial é um contraponto é a ideia de uma decisão baseada apenas no silogismo lógico-formal, visto que para os realistas os juízes tomam suas decisões em seus impulsos que possuem raízes em fatores políticos, econômicos, sociais e sobretudo da sua própria idiossincrasia e não só por 
dedução lógica, pelo contrario primeiro se decide e depois a decisão é submetida a uma racionalização lógica.(FREITAS, 2015, p.89).

Por conseguinte, a atuação atípica dos tribunais brasileiros, especialmente a do Supremo Tribunal Federal, têm transformado essas promessas formais, ideologias a serem conquistadas em direitos efetivos, essa atuação é positiva na medida em que possibilita a concessão de direitos a muitas minorias estigmatizadas como os presidiários, todavia se revela o meio inadequado para a efetivação dos direitos humanos no Brasil, uma vez que atribuir essa responsabilidade a discricionariedade do poder judiciário é temerário, visto que ele não está livre das influencias ideológicas, politicas e da corrupção generalizada que o Brasil vem enfrentando.

\section{Conclusão}

Os Direitos Humanos reconhecidos e positivados nas Constituições Modernas Democráticas são fruto de longo processo histórico e das lutas sociais, foram séculos até eles fossem reconhecidos e positivados nos ordenamentos jurídicos ocidentais. No Brasil, o reconhecimento e a positivação dos Direitos Humanos em nossa Carta maior é fruto de um processo de redemocratização recente e da instituição do jovem Estado Democrático de Direito pela Constituição de 1988. A procura de um fundamento absoluto para os Direitos Humanos é uma ilusão e pode mascarar posições conservadoras e impedir o desenvolvimento de novos direitos, além disto, no lugar de um fundamento absoluto, inquestionável, devemos buscar a sua prática, a efetividade desses direitos e os meios de protegê-los.

A principal dificuldade enfrentada pelos Direitos humanos, ou mesmo os Direitos fundamentais (que são os direitos humanos positivados no âmbito do Estado) diz respeito a sua aplicabilidade e a sua coercibilidade no âmbito internacional. Assim sendo nosso maior desafio é proteger esses direitos, e nossa maior questão passa a ser qual a forma mais segura de garantir esses direitos, uma vez que apesar de estarem consagrados em solenes declarações, eles são violados diariamente seja na esfera do Estado ou na internacional, o maior problema de nossa época não se esses direitos são universais, relativos, históricos, ou mesmo sua fundamentação, reconhecimento ou positivação, mas sim a sua garantia.

O reconhecimento e positivação de tais direitos no Brasil não se mostrou como meio suficiente para a garantia de sua efetividade e o grande desafio enfrentado pelo Brasil na atualidade é a sua concretização, a materialização desses direitos essências a dignidade humana, a aplicação de direitos de tamanha relevância não pode ficar condicionada a discricionariedade do poder judiciário que está sujeito as interferências políticas, esse 
conteúdo político pode transformar o poder judiciário em ditadura institucional que atende aos interesses de um partido ou grupo e tornar os direitos humanos um discurso político a serviço de interesses particulares o que sem duvidas é uma ameaça ao Estado Democrático de Direito.

Sob a perspectiva do realismo jurídico, que possui como principal característica a preocupação com a efetividade, com a aplicação prática dos Direitos a hipótese aqui defendida foi confirmada, os direitos humanos sob a perspectiva do realismo jurídico não são direitos no Brasil, visto que carecem de aplicação concreta.

No entanto, a atuação atípica dos tribunais brasileiros, especialmente a do Supremo Tribunal Federal, têm transformado essas promessas formais, ideologias a serem conquistadas em direitos efetivos, essa atuação é positiva na medida em que possibilita a concessão de direitos a muitas minorias estigmatizadas como os presidiários, todavia se revela o meio inadequado para a efetivação dos direitos humanos no Brasil, atribuir essa responsabilidade a discricionariedade do poder judiciário é temerário, visto que ele não está livre das influências ideológicas, politicas e da corrupção generalizada que o Brasil vem enfrentando, os Direitos humanos não podem ser utilizados como mecanismo de dominação e discurso de justificação das desigualdades, sob pena de perder o seu objeto central que é a garantia da dignidade humana.

Destarte, não podemos deixar de considerar as ponderações realizadas por Lorena de Melo Freitas de que os direitos humanos tem sido um discurso político-jurídico e quase retórico que enaltece a própria ordem jurídica e não podem ser elevados ao patamar de tábua de salvação da humanidade, do direito e da sociedade, uma vez que o próprio direito não pode ser percebido sem as desigualdades econômicas e sociais sob as quais ele fundamenta, uma vez que ele é o meio de legitimação da propriedade privada de bens.

Por conseguinte, a pergunta que nos fica é quais são os humanos fins (objeto) dos DDHH?. Não são todos os humanos que figuram efetivamente como seus destinatários, para alguns humanos apenas as garantias formais são aplicadas é a sociedade paradoxal e negativa mundial quem define quem é de um modo geral um ser humano e por consequência quais são os Direitos Humanos. Dentro desta perspectiva crítica e realista dos Direitos humanos observamos que o discurso a respeito dos DDHH não é um discurso neutro.

\section{Referências}

BRASIL. Constituição da República Federativa do Brasil. Brasília: Senado, 1988. 
BRASIL. Supremo Tribunal Federal. ADPF n. 347 - DF. Rel. Min. Marco Aurélio. Informativo STF, $\quad$ n. $798 . \quad$ Disponível <http://www.stf.jus.br/arquivo/informativo/documento/informativo798.htm>. Acesso em: 05.07.2018.

BARROSO, Luis Roberto de. Judicialização, Ativismo Judicial e Legitimidade Democrática, artigo de 2008.2 Disponível <http://www.direitodoestado.com.br/artigo/luis-robertobarroso/retrospectiva-2008 judicializacao-ativismoelegitimidade-democratica>. Acesso em: 10. 07.2018.

BOBBIO, N. A Era dos Direitos. Tradução Carlos Nelson Coutinho; apresentação de Celso Lafer. Nova ed. Rio de Janeiro: Elsevier, 2004.

BOBBIO, N. O Positivismo Jurídico: Lições de Filosofia do Direito. Trad. Marcio Pugliese, Edson Bini, Carlos. E. Rodrigues. São Paulo; ícone, 1995.

CAMPOS, Carlos Alexandre de Azevedo. Da Inconstitucionalidade por Omissão ao “Estado de Coisas Inconstitucional". 2015. Tese de Doutorado em Direito Público. Faculdade de Direito - Universidade do Estado do Rio de Janeiro.

CAMPOS. Carlos Alexandre de Azevedo. O Estado de Coisas Inconstitucional e o litígio estrutural. 2015. Disponível em:<http://www.conjur.com.br/2015-set-01/carloscamposestado-coisas-inconstitucional-litigioestrutural >.Acesso em: 06.07.2018.

CANOTILHO, J. J. Gomes. Direito Constitucional e Teoria da Constituição. Coimbra: Almedina, 2002.

CARDOZO, Benjamin. The Nature of Judicial Process. New Haven: Yale University Press, 1991.

CASTRO, Flávia Lages de. História do direito Geral e do Brasil. 9.ed. Rio de Janeiro: Lumen Juris, 2012.

COMPARATO, Fábio Konder. A afirmação histórica dos direitos humanos. $2^{\mathrm{a}}$ tiragem. $3^{\mathrm{a}}$ ed. São Paulo: Saraiva, 2003.

DOUZINAS, Costas. O fim dos direitos humanos. Tradução Luzia Araújo. São Leopoldo: Unisinos, 2009.

LAFER, Celso. A reconstrução dos direitos humanos: um diálogo com o pensamento de Hannah Arendt. São Paulo: Companhia das Letras, 1988.

FEITOSA, Enoque; FREITAS, Lorena. Direito e Filosofia da Práxis: A Teoria do Direito entre prescrição e descrição. In: SOBREIRA FILHO, Enoque Feitosa; BELLO, Enzo; SILVA, Paulo Henrique Tavares da. (Coords.) Marxismo e Direito: Anais do XXIII Congresso Nacional do CONPEDI. João Pessoa: EdUFPB, 2014. Disponível em:<http://publicadireito.com.br/artigos/?cod=78af92f2de822f11 >. Acesso em 01 out 2018.

FEITOSA, Enoque; FREITAS: Lorena. Marxismo, realismo e direitos humanos. João Pessoa: Editora Universitária da UFPB 2012.

SARLET, Ingo Wolfgang. A eficácia dos direitos fundamentais. Porto Alegre: Livraria do Advogado, 1998.

SCHWARZ, Roberto. Ao vencedor as batatas. 5 ed., São Paulo, Editora 34,2005. 